\title{
Margaret Jane Kidnie, ed. A Woman Killed with Kindness, by Thomas Hey- wood. London: Bloomsbury, 2017. Pp xviii, 301. Paperback $£ 14.99$. ISBN: 9781904271581.
}

\section{ELEANOR LOWE}

\section{Oxford Brookes University}

This is the first edition of $A$ Woman Killed with Kindness since Martin Wiggins's edition for Oxford World's Classics in 2008. Margaret Jane Kidnie's new edition of the play reminds readers of Lukas Erne's point that Heywood was 'The second most published playwright [after Shakespeare]' with forty-nine editions to his name (according to Erne's calculations), and that his 'prominence in print is easily overlooked' (69). Kidnie notes that Heywood never published his work in folio (unlike that of some of his contemporaries) which 'in part' explains how 'Only about one-tenth of Heywood's putative 220 plays are extant', despite Francis Meres noting him as being 'the best for comedy' in 1598 (64-5). Heywood wrote the play at a crucial moment of national and theatrical disruption: soon after Henslowe made the final payments for the writing of the play, Elizabeth I died. The theatres closed and remained so through a period of plague, after which Worcester's men became the Queen's men and moved north of the river (72).

The introduction provides an accessible discussion of a range of issues pertinent to the play's subject matter and context (such as household dynamics, marriage and adultery, and the source material), as well as consideration of Heywood's writing and the circumstances of the play's earliest performances. The edition does well to be mindful of both the play as a printed text (and its evolution in print) and as a performed script. Discussion of staging issues is thorough and clear. The edition is interested in both modern and original performance possibilities, supplemented with helpful reflection on Heywood's stagecraft and performance history. There is a full discussion of the play's performance history with images from six different productions, from the earliest in 1913 (directed by Jacques Copeau) to the National Theatre production in 2011 (directed by Katie Mitchell). Kidnie includes succinct information concerning both textual and performance issues throughout the on-page annotations.

There is also a helpful section on the play's sources and its status as a 'domestic tragedy' (including a history of that discussion and its usefulness as a label). Kidnie points out that 'Ideologically and theatrically, the term "domestic tragedy", at least as it relates to Heywood's play, seems simultaneously too vague and too constraining' because the term has unhelpful modern associations which might 
eclipse early modern understandings of the household (54). She pays particular attention to the subplot, which scholars have for a long time dismissed, and Kidnie demonstrates how well it comments on and reflects the main plot.

Kidnie's analysis of Q1 draws attention to indications that 'Heywood changed his mind about a few details as he wrote the script' (106): for example, the naming of Sir Charles Mountford's sister as Jane instead of Susan in scenes 3 and 14, and the opening stage direction which announces the entrance of Anne Frankford by her maiden name of Acton (106). Kidnie points out that some of these changes and inconsistences 'provide a useful glimpse into the creative process'; elsewhere, she argues that Heywood's difficult handwriting was a potential cause of confusion and textual complication which led to errors in printing, such as in four examples concerning the specialist hunting terminology in scene 3 (108).

The title page of Q2 (together with discrepancies between its content and that of Q1) occupies the heart of the textual discussion. The 1617 edition describes itself as 'The third Edition' and Kidnie identifies the numbering of editions as a 'relatively new publishing trend' (111). She posits three possible scenarios to explain this detail, before presenting the differences between Q2 and Q1, and finally proposing the theory that both Q1 and Q2 are based on an original quarto labelled Q0 which came before both extant printed texts. Kidnie identifies several issues that Q2 resolves within Q1 which relate to 'both narrative fiction and metre' (for example, an incorrect entry for Sir Francis is altered to cue Sir Charles), as well as changes which are 'less corrections than interpretative alterations' (112). The largest difference in presentation is between the two editions' fonts: Q2 has a larger font, causing problems with the verse line exceeding the measure, so that the compositor had to alter the lineation and abbreviate speech prefixes, typically in identifying Frankford as Fran (compared with Q1's Frank) (114). Kidnie notes K.M. Sturgess's identification of the Q2 compositor as Compositor B of Shakespeare's First Folio, but is cautious about fully accepting this attribution (115-16).

Kidnie's analysis of the differences between Q1 and Q2's approach to exit directions leads towards her rationale for there being a third, lost edition (as opposed to the Q2 title page being incorrect): 'that Q2 was not based on a copy of Q1, either directly or by means of an intervening, now lost, reprint of that edition' (118). In a section headed 'Inferring a Now-Lost First Edition' she argues that the 'peculiar combination of similarities and differences between these two editions can be explained by accepting Q2's claim to be the third edition, and positing that the lost edition preceded both of the surviving editions, and was the copy from which each was printed' (118-19). She points out that Q1 did not 
exactly reproduce Q0, just as Q2 introduced its own changes to the text. The lack of announcement on Q1's title page as a 'second edition' does not discredit this theory since even in 1617 the provision of such information was relatively new. That only one copy of Q1 is extant reminds us how close we are to having only one extant quarto of the play at all (Q2). Kidnie further considers Sonia Massai's identification of 'the hand of an annotating reader' who is familiar enough with the play to make corrections based on textual errors which impact on the play's action and dramatic sense and who is 'clearly correcting for sense' $(124,126)$. At the end of her analysis, Kidnie marks the annotating hand as useful in deducing the play's textual transmission and in providing information about the evolution of the practices of the Jaggard printing-house (129). This detailed discussion goes some way to explain and justify Kidnie's main decision in her statement of editorial principles to base her edition on Q1 'since, by comparison to Q2, its text diverges less from the lost Q0' (129).

Particularly valuable are the notes to scene 3 which provide explanation of the textual issues pertaining to the falconry terms and gloss their meanings with reference to Heywood's source, William Gryndall's redaction of The Book of St Albans titled Hawking, Hunting, Fouling, and Fishing (1586, rpt 1596); see, for example, notes on 'chirk' (3.8n) and 'her ... bells' (3.9n). The notes also explore some of the key textual issues (such as differences between Q1 and Q2 or other editors' decisions, placement or insertion of stage directions, and inconsistency in speech prefixes), as well as discussing the stage action, both as it might manifest itself upon the early modern stage and with reference to specific realizations in the play's theatre history. These latter discussions help to enrich a reading of the play, aiding the reader to visualize possible staging of the text. Kidnie is ever open to the play text's dual purpose as an object for readers in print and a theatrical collaboration for spectators, actors, and directors on the stage, both in the play's past life and its potential future.

Several notes and parts of the introduction discuss the play's very flexible use of stage space. In scene 4, for example, where the opening stage direction requires Frankford to enter 'in a study', Kidnie explains this as being easily achievable with a single prop book (rather than a fully-furnished study), since the action of the scene moves from Frankford's private reflection to a more public space. Similar points of discussion in the notes and introduction occur for scene 17, which begins outside the manor allocated to Anne Frankford but moves inside at the stage direction where she enters 'in her bed' (17.38 sd). In a useful section of the introduction titled 'Heywood's Stagecraft', Kidnie discusses the 'ease with which Heywood summons up and equally quickly discards fictional space' which 'is 
particularly evident in shifts in location that occur in the middle of scenes' (75). Kidnie also explores the performance of domestic geography in scene 13 in which Frankford returns to his house with several keys, each of which he introduces in order to map his imminent journey from the outside gate through the house to his bedroom door. Kidnie concludes that 'Heywood's staging, here and elsewhere, is flexible and efficient, slipping between localized and unlocalized spaces with a freedom enabled by the playwright's skilful use of theatrical convention and dramatic language' (83). Insights of this kind, with their dual attention to the textual and theatrical detail of the play, will ensure the edition is useful to a wide range of scholars and students. 